This item was submitted to Loughborough's Research Repository by the author.

Items in Figshare are protected by copyright, with all rights reserved, unless otherwise indicated.

Towards a total synthesis of the manadomanzamine alkaloids: the first asymmetric construction of the pentacyclic indole core

PLEASE CITE THE PUBLISHED VERSION

PUBLISHER

(c) Elsevier

LICENCE

CC BY-NC-ND 4.0

REPOSITORY RECORD

Allin, Steven M., Liam J. Duffy, Philip C. Bulman Page, Vickie McKee, and Michael J. McKenzie. 2019.

"Towards a Total Synthesis of the Manadomanzamine Alkaloids: The First Asymmetric Construction of the Pentacyclic Indole Core". figshare. https://hdl.handle.net/2134/2892. 
This item was submitted to Loughborough's Institutional Repository by the author and is made available under the following Creative Commons Licence conditions.

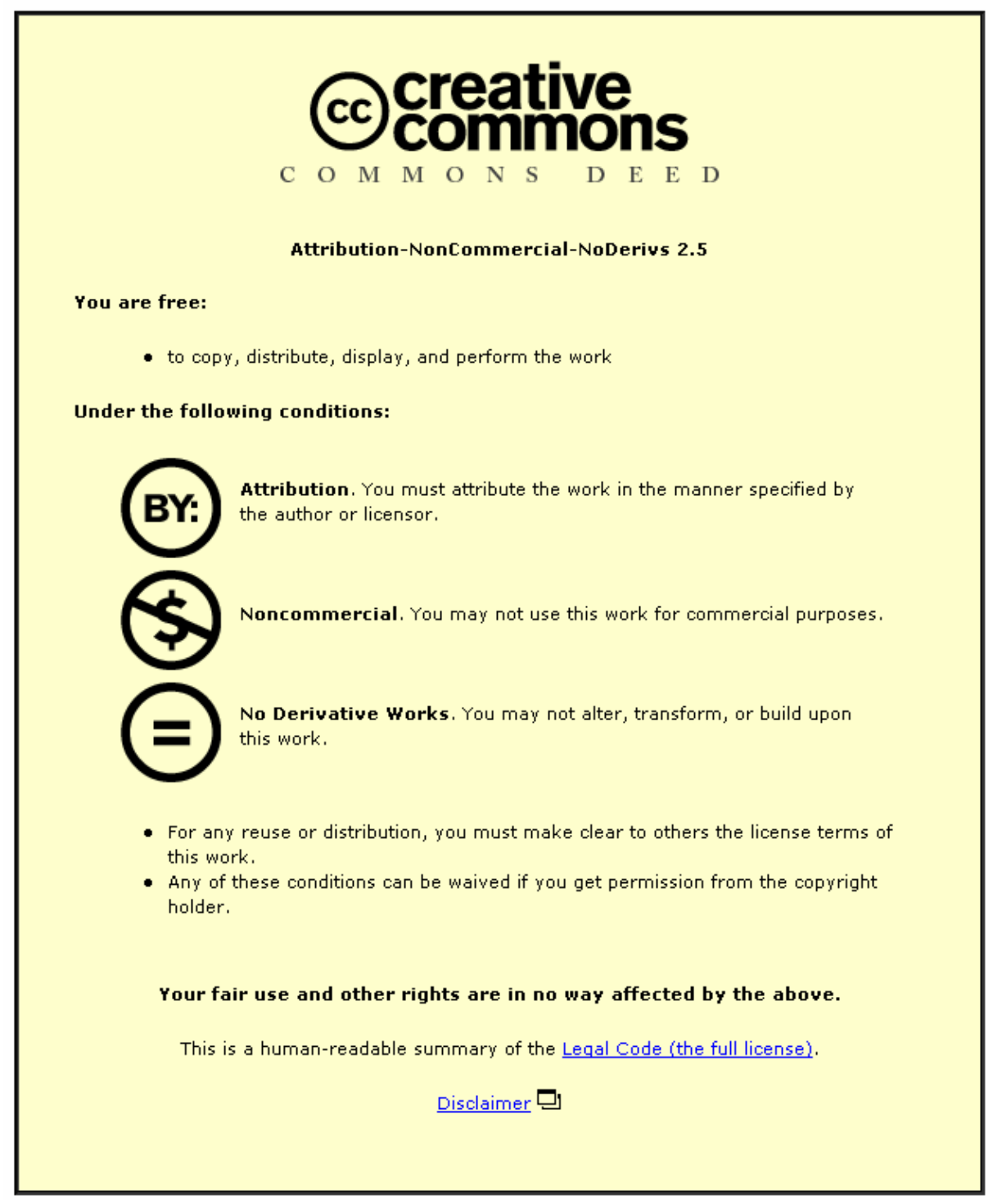

For the full text of this licence, please go to: http://creativecommons.org/licenses/by-nc-nd/2.5/ 


\title{
Towards a total synthesis of the manadomanzamine alkaloids: the first asymmetric construction of the pentacyclic indole core
}

\author{
Steven M. Allin, ${ }^{\mathrm{a} *}$ Liam J. Duffy, ${ }^{\mathrm{a}}$ Philip C. Bulman Page, ${ }^{\mathrm{a}}$ Vickie McKee ${ }^{\mathrm{a}}$ \\ and Michael J. McKenzie \\ ${ }^{a}$ Department of Chemistry, Loughborough University, Loughborough, Leicestershire, LE11 3TU, UK. \\ ${ }^{b}$ Charnwood Molecular Ltd., The Heritage Building, Prince William Road, Loughborough LE11 5GA, UK.
}

\begin{abstract}
We report a highly diastereoselective approach for the synthesis of the pentacyclic indole core of the manadomanzamine alkaloid skeleton, with complete control over the relative and absolute stereochemistries at the three contiguous stereocentres at ring positions 1 , 10, and 24 , from a readily available chiral template.
\end{abstract}

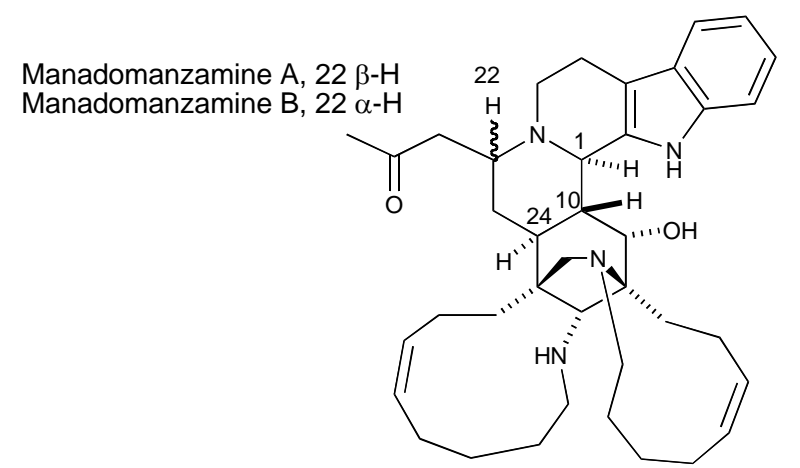<smiles>O=C1CCc2c([nH]c3ccccc23)[C@@H]2CCCC[C@H]2C1</smiles>

1

In 2003 Hamann and co-workers reported the isolation of two novel marine alkaloids, manadomanzamine $\mathrm{A}$ and $\mathrm{B}$, from the Indonesian sponge Acanthostrongylophora sp. ${ }^{1}$ These compounds were found to exhibit strong activity against myobacterium tuberculosis (Mtb) with MIC values of 1.9 and $1.5 \mu \mathrm{g} / \mathrm{mL}$ respectively. In addition these alkaloids show activities against HIV-1 and AIDS opportunistic infections. The recent increasing occurrence and threat of tuberculosis has renewed interest in the development of anti-tuberculosis agents, since the W.H.O. estimates that currently onethird of the worlds population is infected with TB, with 3.1 million deaths occurring per annum. Further, such a lead compound with activity against both HIV-1 and AIDS opportunistic infections is of significant value. A plausible biosynthetic pathway to the manadomanzamines has been proposed from the more common manzamine alkaloids. ${ }^{1}$ To date no total synthesis of the manadomanzamines has been reported, and indeed a general and stereoselective approach to simpler core analogues, including $\mathbf{1}$, a dodecahydrobenz[a]indolo[3,2-h]quinolizine, is still lacking. This pentacyclic ring system, sometimes referred to as an "inside yohimbane," has previously been prepared in racemic fashion by Morrison and co-workers., ${ }^{2}$ and has been observed as a by-product in approaches to racemic yohimbine and reserpine by Martin. ${ }^{3}$ Our research group, and others, have had considerable success in recent years in the development of asymmetric routes to several important heterocyclic templates, based around the development of highly diastereoselective $N$-acyliminium cyclization strategies. ${ }^{4}$ Our own recent applications of this methodology in natural product synthesis have included targets from the

\footnotetext{
* Corresponding author. S.M.Allin@lboro.ac.uk
} 
erythrina group of alkaloids ${ }^{4 f, i}$ and several indole alkaloids. ${ }^{4 a, d, e, g}$ In this communication we report a highly diastereoselective construction of the manadomanzamine core, $\mathbf{1}$, with complete stereocontrol control over the three contiguous stereocentres at ring positions 1,10 , and $24 .{ }^{5}$ Our retrosynthetic analysis of the pentacyclic target 1, presented in Scheme 1, led back to the use of (S)-tryptophanol 3, as both a source of indole and as the chiral auxiliary in the proposed $N$-acyliminium cyclization.

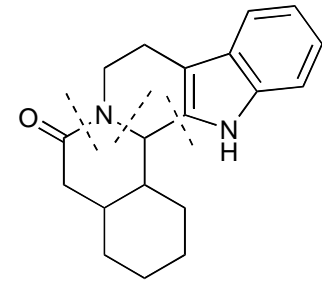

1<smiles>O=CC1CCCCC1CC(=O)O</smiles>

2

\section{Scheme 1. Our retrosynthetic analysis of the manadomanzamine core.}

The bifunctional substrate $\mathbf{2}$ was prepared by an homologation reaction through Wittig functionalization of commercially available ketone 4, followed by hydrolysis of the resulting enol ether (Scheme 2). Compound 2 is isolated as a mixture of the cis and trans isomers (ca. 1:3 respectively), with the trans predominating. ${ }^{2}$<smiles>CCOC(=O)CC1CCCCC1=O</smiles>

4<smiles>CC=C1CCCCC1CC(=O)OCC</smiles>

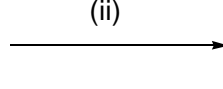<smiles>O=CC1CCCC[C@@H]1CC(=O)O</smiles>

rac-2

Scheme 2. (i) $\mathrm{CH}_{3} \mathrm{OCH}_{2} \mathrm{PPh}_{3} \mathrm{Cl}$ (2.0 eq.), $\mathrm{KOBu}^{t}$ (3.0 eq), toluene, $\mathrm{RT}$ (64\% yield); (ii) $2 \mathrm{~N} \mathrm{HCl}, 55{ }^{\circ} \mathrm{C}, \mathrm{THF} / \mathrm{H}_{2} \mathrm{O}$ (3:1), (99\% yield).

Aldehyde 2, a racemate, was subjected to the standard cyclocondensation reaction with (S)tryptophanol. ${ }^{4 a, d, g, e}$ The use of racemic multi-functional aldehyde substrates in stereoselective condensation reactions has been much explored by Bosch and Amat. ${ }^{6}$ In our hands, the condensation of racemic cis/trans-2 with (S)-tryptophanol under Dean-Stark conditions in toluene for 24 hours gave a 1:1 mixture of two readily separable diastereoisomers 5a,b in $69 \%$ overall yield (Scheme 3). Presumably the dynamic kinetic resolution that is well known for such substrates under cyclocondensation conditions occurs here to give the preferred trans orientation in $2 .{ }^{6}$

The relative stereochemistry of $\mathbf{5 a}$ was determined by n.O.e studies on the isolated compound ${ }^{7}$ and that of isomer $\mathbf{5 b}$ by $\mathbf{X}$-ray crystallographic analysis. Whereas diastereoisomer $\mathbf{5 a}$ has the correct relative and absolute stereochemistry at what will become the C-10 and C-24 positions of the manadomanzamine natural products, isomers such as $\mathbf{5 b}$ may prove useful in future analogue generation studies. The stereochemistry at the noted C-1 position is of no significance at this stage, as this corresponding aminal centre will form a planar iminium carbon atom in subsequent reaction steps. The stereochemical outcome of the cyclocondensation reaction shown in Scheme 3 can be rationalized 
by considering the formation of the aminal intermediates from each enantiomer of the aldehyde substrate $\mathbf{2}$, formed en route to the lactam products $\mathbf{5 a , b}$, as highlighted in Scheme 3.<smiles>O=C(O)C[C@H]1CCCC[C@H]1O</smiles>

$2 a$<smiles>O=C[C@H]1CCCC[C@H]1CC(=O)O</smiles>

2b<smiles>O=CC1CCCCC1C(=O)O</smiles><smiles>C1CCC1</smiles>

S-3
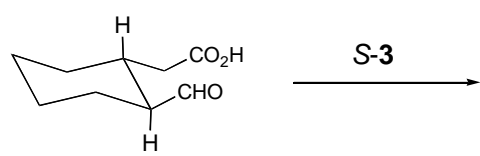

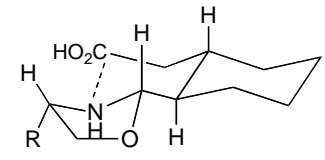

$6 a$

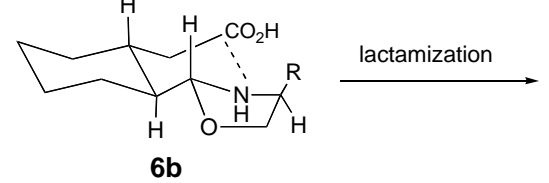

6b

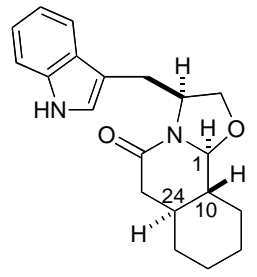

$5 a$

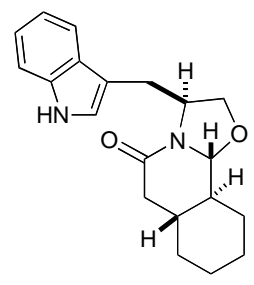

$5 b$

Scheme 3. Cyclocondensation/resolution of rac-aldehyde 2.

The preferred aminal conformations 6a,b allow a favoured trans-decalin-like arrangement of the reactive intermediate, with an all-equatorial substituent pattern, ${ }^{6}$ prior to irreversible lactamization, with the $\mathrm{H}$-atom at the aminal carbon centre preferred in an axial arrangement, leading only to minimal diaxial interactions in these conformations.

With individual asymmetric building blocks $\mathbf{5 a}$ and $\mathbf{5 b}$ in hand, we turned our attention to the proposed $\mathrm{N}$-acyliminium cyclization step. These asymmetric building blocks were separately subjected to acidinduced cyclization reactions promoted by $2 \mathrm{M} \mathrm{HCl}$ in EtOH at room temperature for 18 hours. Under these conditions, substrate $\mathbf{5 a}$ underwent clean cyclization in $73 \%$ yield to a single diastereoisomer of the desired product 8a (Scheme 4). N.O.e experiments subsequently established that the pentacyclic product 8a was generated with the correct relative and absolute stereochemistries at ring positions 1, 10 and 24 as required for the manadomanzamine natural product skeleton. ${ }^{8}$

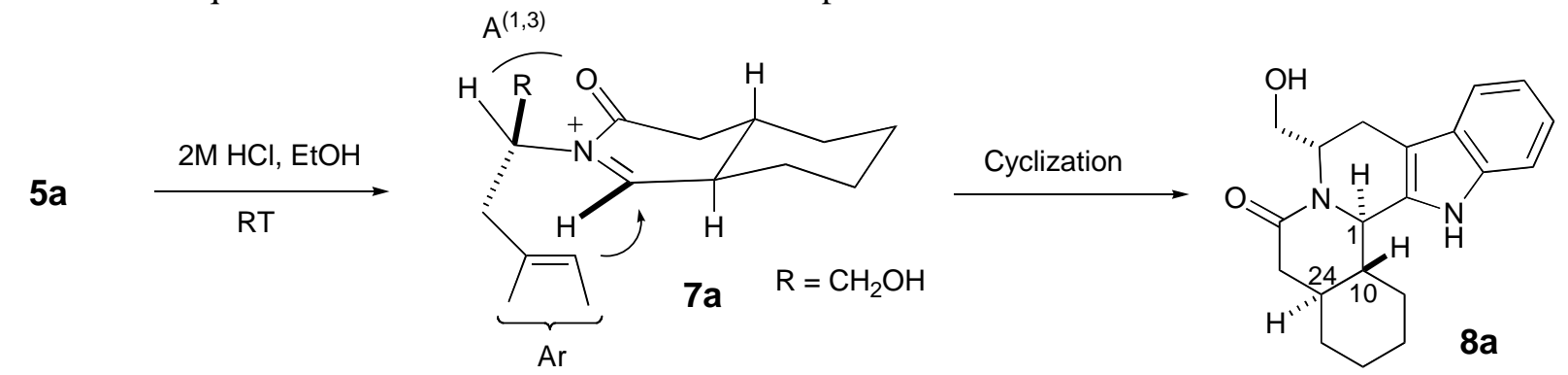

Scheme 4. Access to the manadomanzamine core.

Such highly diastereoselective cyclization reactions of the indolyl nucleus onto $N$-acyliminium intermediates are now well established, ${ }^{4 a, d, e, g, 0}$ and the usual rationalization of the observed stereochemical induction holds true in this particular case. The stereocontrol arises from a preferred conformation, 7a, having minimal $\mathrm{A}^{(1,3)}$ strain between the $\mathrm{H}$-atom at the stereogenic centre of the tryptophanol moiety and the lactam carbonyl group in the transition state. ${ }^{9}$ Cyclization of the indolyl nucleus thus takes place from a pro-equatorial orientation, leading to a seemingly preferred axial 
orientation of all three $\mathrm{H}$-substituents at positions $\mathrm{C}-1,10$ and 24 in compound $\mathbf{8 b}$, matching the natural product stereochemistry at these three contiguous asymmetric centres.

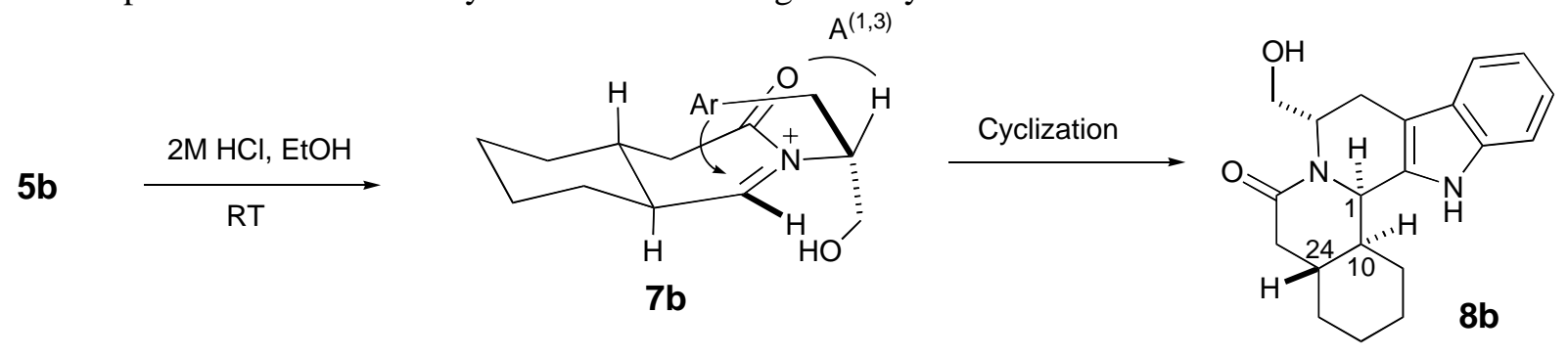

Scheme 5. Cyclization of $5 \mathbf{b}$.

In the case of lactam substrate $\mathbf{5 b}$, as outlined in Scheme 5, cyclization proceeded in comparable (75\%) yield to give a single product diastereoisomer, which was subsequently determined (n.O.e) to have the relative stereochemistry shown in structure $\mathbf{8 b} .{ }^{10}$ Again the stereocontrol arises through the preferred conformation $\mathbf{7 b}$, minimizing the $\mathrm{A}^{(1,3)}$ strain between the $\mathrm{H}$-atom at the stereogenic centre of the tryptophanol moiety and the lactam carbonyl group, despite the fact that the transition state must lead to a pro-axial attack onto the iminium species by the indolyl nucleus.

In summary, we report the first highly asymmetric synthesis of the pentacyclic core of the manadomanzamine alkaloids in only two linear synthetic steps from readily available reagents. Our route allows the controlled formation of the correct relative and absolute stereochemistries at the three contiguous chiral centres at positions C-1, C-10, and C-24 of the heterocyclic skeleton. Although not described in this communication, we have established and reported several routes for removal of the hydroxymethyl auxiliary group from similar heterocyclic templates. ${ }^{4 \mathrm{~d}, \mathrm{f}}$ Our current work is devoted to the development of this synthetic route to allow access to more highly functionalized intermediates and thus to a total synthesis of the manadomanzamines and their synthetic analogues, and will be reported in due course.

Acknowledgments: The authors wish to thank Loughborough University for facilities and financial support, and the EPSRC and Charnwood Molecular Ltd for studentship support to L. J. Duffy.

\section{References and Notes}

1. Peng, J.; Ju, J.-F.; Kazi, A.B.; Li. Z.; Avery, M.; Peraud, O.; Hill, R.T.; Franzblau, S.G.; Zhang, F.; Schinazi, R.F.; Wirtz, S.S.; Tharnish, P.; Kelly, M.; Wahyuono, S.; Hamann, M.T. J. Am. Chem. Soc. 2003, 125, 13382-13386.

2. Morrison, G.C.; Cetenko, W.A.; Shavel, J. J. Org. Chem. 1967, 32, 2768-2772.

3. Martin, S.F.; Rueger, H.; Williamson, S.A.; Grzejszczak, S. J. Am. Chem. Soc. 1987, 109, 61246134.

4. (a) Allin, S.M.; Khera, J.S.; Witherington, J.; Elsegood, M.R.J. Tetrahedron Lett. 2006, 47, 57375739; (b) Allin, S.M.; Duffy, L.J.; Page, P.C.B.; McKee, V.; Edgar, M.; McKenzie, M.J.; Amat, M.; 
Bassas, O.; Santos, M.M.M., Bosch, J. Tetrahedron Lett. 2006, 47, 5713-5716; (c) Allin, S.M.; Khera, J.S.; Thomas, C.I.; Witherington, J.; Doyle, K; Elsegood, M.R.J.; Edgar, M. Tetrahedron Lett. 2006, 47, 1961-1964; (d) Allin, S. M.; Thomas, C. I.; Allard, J.E.; Doyle, K.; Elsegood, M. R. J. Eur. J. Org. Chem. 2005, 4179-4186; (e) Allin, S. M.; Thomas, C. I.; Doyle, K.; Elsegood, M. R. J. J. Org. Chem. 2005, 70, 357-359; (f) Allin, S.M.; Streetley, G.B.; Slater, M.; James, S.L.; Martin, W.P. Tetrahedron Lett. 2004, 45, 5493-5496; (g) Allin, S. M.; Thomas, C. I.; Allard, J. E.; Doyle, K.; Elsegood, M. R. J. Tetrahedron Lett. 2004, 45, 7103-7105; (h) Allin, S. M.; Thomas, C. I.; Allard, J. E.; Duncton, M.; Elsegood, M. R. J.; Edgar, M. Tetrahedron Lett. 2003, 44, 2335-2337; (i) Allin, S.M.; James, S.L.; Elsegood, M.R.J.; Martin, W.P. J. Org. Chem. 2002, 67, 9464-9467; (j) Allin, S. M.; Vaidya, D. G.; James, S. L.; Allard, J. E.; Smith, T. A. D.; McKee, V.; Martin, W. P. Tetrahedron Lett. 2002, 43, 3661-3663; (k) Allin, S. M.; James, S. L.; Martin, W. P.; Smith, T. A. D, Elsegood, M. R. J. J. Chem. Soc., Perkin Trans. 1 2001, 3029-3036; (l) Allin, S. M.; James, S. L.; Martin, W. P.; Smith, T. A. D. Tetrahedron Lett. 2001, 41, 3943-3946; (m) Allin, S. M.; Northfield, C. J.; Page, M. I.; Slawin, A. M. Z. Tetrahedron Lett. 1998, 39, 4905-4908.

Also see the related work of Lete, Amat and Bosch, for example: (n) Garcia, E.; Arrasate, S.; Lete, E.; Sotomayor, N. J. Org. Chem. 2005, 70, 10368-10374; (o) Bassas, O.; Llor, N.; Santos, M.M.M.; Griera, R.; Molins, E.; Amat, M.; Bosch, J. Org. Lett. 2005, 7, 2817-2820. For an excellent recent review of $\mathrm{N}$-acyliminium cyclizations see: (p) Maryanoff, B.E.; Zhang, H.-C.; Cohen, J.H.; Turchi, I.J.; Maryanoff, C.A. Chem. Rev. 2004, 104, 1431-1628.

5. In this paper we refer to the manadomanzamine numbering scheme when referring to the corresponding dodecahydrobenz[a]indolo[3,2-h]quinolizine positions simply for ease of comparison.

6. Amat, M.; Bassas, O.; Llor, N.; Canto, M.; Perez, M.; Molins, E.; Bosch, J. Chem. Eur. J. 2006, 12, 7872-7881; and references cited therein.

7. For compound $\mathbf{5 a}$, in summary, the protons at ring positions 1 and 24 give a positive n.O.e, to each other, but neither gives an n.O.e. to the proton at ring position 10 .

8. For compound $\mathbf{8 a}$, in summary, the protons at ring positions 1 and 24 give a positive n.O.e, to each other, but neither gives an n.O.e. to the proton at ring position 10. The hydroxymethyl group $\left(\mathrm{CH}_{2}\right)$ gives a positive n.O.e to the proton at ring position 1 .

9. Garcia, E.; Arrasate, S.; Lete, E.; Sotomayor, N. J. Org. Chem. 2005, 70, 10368-10374 and references cited therein; Allin, S. M.; Northfield, C. J.; Page, M. I.; Slawin, A. M. Z. Tetrahedron Lett. 1998, 39, 4905-4908. 
10. For compound $\mathbf{8 b}$, in summary, the protons at ring positions 1 and 10 give a positive n.O.e, to each other, but neither gives an n.O.e. to the proton at ring position 24 . The hydroxymethyl group $\left(\mathrm{CH}_{2}\right)$ gives a positive n.O.e to the proton at ring position 1. 